\title{
AN IMPROVED GUIDANCE ALGORITHM FOR SOLID PROPELLENT BALLISTIC MISSILES
}

\author{
S.GHONIEMY * M. TANTAWY * * M.ELLEITHY ***
}

\section{ABSTRACT}

Due to production tolerences and off-nominal environmental conditions, the thrust time profile of solid propellant rocket motors suffers from high uncertainties in both magnitude and This behaviour leads to higher uncertainties in the motion parameters of the missile at the shut-off (burn-out) point. Accordingly, the impact point is highly erroneous. lops a guidance and control strategy for the effects of the above-mentioned uncertainties in such a way as to minimize impact errors.

* Asc.Prof. Guid.Dep.M.T.C.

** Asc.Prof. D.S.S.C.

$\star \star * \mathrm{Ph} . \mathrm{D}$.

Air Def.College 


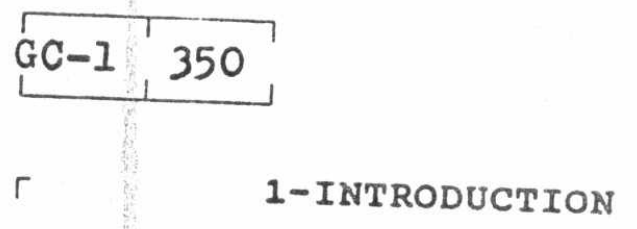

FOURTH ASAT CONFERENCE

11-16 May 1991, CAIRO

The performance of ballistic missile systems is measured in three capability.

Impact accuracy is influenced mainly by:

- Computation errors

- Steering and burn out errors

- Gravitational anomalies

- Re-entry errors

Guidance and control strategies are designed to steer the mission) for a specified state (corresponding to a specified achieve suitable impact by minimizatior ver at shut-off to missile from the target point. Ballistic missile system desi

of liquid propellent engineslgners have concentrated on the use that they can be readily recognizing that their advantage is of handling ease has generated inled. However, inherent advantage solid propellents. Due to production nominal environmental condition tolerences and offsolid propellant rocket thrust time profile of in both magnitude and bu motors suffers from high uncertainties higher uncertainties in these uncertainties lead to at the shut-off (burn-out) motion parameters of the missile is highly erroneous. This paper Accordingly, the impact point strategy for compensating contops a guidance and control uncertainties in such a way of the above mentioned

\section{2-MODELING AND SIMULATION}

\section{1-Reference coordinates and vector Transformations} The reference coordinate systems used through out this study are
shown in Figure.1.

a vector $A_{e}$ in earth coordinate system body coordinate system to matrix [ME]

$[M E]=\left[\begin{array}{lll}I_{1} & J_{1} & K_{1} \\ I_{2} & J_{2} & K_{2} \\ I_{3} & J_{3} & K_{3}\end{array}\right] ;[M E]^{-1}=[M E]^{T}=[E M]$

This transformation contains three intermediate transformations;
- Missile-Fire

- Fire- Local

- Local-

transformations. 


\section{2- Six degrees of Freedom Motion Equations}

The vectorial system of equations describing the ballistic missile motion in space is as follows:

$\dot{\overline{\mathrm{R}}}_{\mathrm{m}}=\overline{\mathrm{R}}_{\mathrm{m}}+\overline{\mathrm{W}}_{\mathrm{e}} \cdot \overline{\mathrm{R}}_{\mathrm{m}}$

$\dot{\vec{V}}_{e}=\overline{\mathrm{V}}_{e}+\overline{\mathrm{W}}_{e} \hat{\bar{V}_{e}}=\overline{\bar{A}}_{e}+\overline{\mathrm{G}}_{e}$

$\dot{\vec{I}}_{m}=\left(\bar{W}_{m e}-\bar{W}_{e}\right) \wedge \bar{I}_{m}$

$\dot{\vec{J}}_{m}=\left(\overline{\mathrm{W}}_{m e}-\overline{\mathrm{W}}_{e}\right) \cdot \overline{\mathrm{J}}_{\mathrm{m}}$

$\dot{\overrightarrow{\mathrm{H}}}_{\mathrm{a}}+\overline{\mathrm{W}}_{\mathrm{m}}-\overline{\mathrm{H}}_{\mathrm{a}}=\overline{\mathrm{T}}_{\mathrm{A}}+\overline{\mathrm{T}}_{\mathrm{T}}$

$\overline{\mathrm{A}}=\left(\overline{\mathrm{F}}_{\mathrm{A}}+\overline{\mathrm{F}}_{\mathrm{T}}\right) / \operatorname{mas}$

$\overline{\mathrm{K}}_{\mathrm{m}}=\overline{\mathrm{I}}_{\mathrm{m}} \cdot \overline{\mathrm{J}}_{\mathrm{m}}$

\section{3-Fire Plane Motion Equations}

The fire plane is defind by the launch point, target point, and earth center. Under the assumptions that:

- the launch point is at $(0,0)$

- the target point is in the north direction

- the missile is roll stabilized such that $W_{x 1}=0$

- the missile is of X-form

- the missile moves in the fire plane with $\Psi=*_{0}=0 ; W_{Y 1}=0$

the equations of motion take the form:

$\dot{x}_{e}=V_{e l}$

$\dot{\mathrm{V}}_{\mathrm{eI}}=\mathrm{A}_{1} \mathrm{I}_{1}+\mathrm{A}_{2} \mathrm{~J}_{1}+\mathrm{G}_{\mathrm{el}}$

$I_{1}=-W_{21} I_{2}\left(I_{1} J_{2}-I_{2} J_{1}\right)$

$J_{1}=-W_{21} J_{2}\left(I_{1} J_{2}-I_{2} J_{1}\right)$

$\dot{\mathrm{W}}_{\mathrm{Z} 1}=\left(\mathrm{T}_{\mathrm{A} 3}+\mathrm{T}_{\mathrm{T} 3}\right) / \mathrm{J}_{22}$

With initial conditions:

$\mathrm{x}_{\mathrm{e}}(0)=0$

$V_{\text {el }}(0)=0$

$I_{1}(0)=\cos \theta_{0}$

$J_{1}(0)=-\sin \theta_{0}$

$w_{Z_{1}}(0)=0$

$$
\begin{aligned}
& \dot{Y}_{e}=V_{e 2} \\
& \dot{V}_{e 2}=A_{1} I_{2}+A_{2} J_{2}+G_{e 2} \\
& \dot{I}_{2}=W_{Z_{1}} I_{I}\left(I_{1} J_{2}-I_{2} J_{1}\right) \\
& \dot{J}_{2}=W_{Z I} J_{1}\left(I_{1} J_{2}-I_{2} J_{1}\right)
\end{aligned}
$$

$$
\begin{aligned}
& Y_{e}(0)=R_{e} \\
& V_{e 2}(0)=0 \\
& I_{2}(0)=\sin \theta_{0} \\
& J_{2}(0)=\cos \theta_{0}
\end{aligned}
$$


r

2.4-Autopilot

To achieve adequate stability and reasonable rapid and well damped response with moderate insensitivity to external disturbances a lateral autopilot; Fig.2.; is designed to control the short period dynamics such that:

$\dot{\delta}_{\mathrm{z}}=-\mathrm{K}_{1} \mathrm{w}_{\mathrm{zl}}+\mathrm{K}_{2} \mathrm{~V}_{\mathrm{a} 2} / \mathrm{V}_{\mathrm{al}}+\mathrm{K}_{3} \delta_{\mathrm{z}}+\mathrm{U}_{\mathrm{d}}$ where $K_{1}, K_{2}, K_{3}$ are determined through pole assignement
technique.

2.5-Mission (Feference Trajectory)

The assumed mission is described through:

$\Gamma_{r}=$ constant $=\theta_{0}$

heice $\quad \dot{\vec{r}}_{\mathrm{r}}=0$

\section{6-Attitude Control}

The attitude control demand is calculated by augmenting the difference between $\Gamma_{r}$ and $\Gamma$ through P.I.compensator. Fig-2 shows the functional block diagram for the closed loop ballistic missile system illustrating the additive compensators employed for improving both short and long period dynamics
behaviour.

This system is simulated under the assumptions:

- launch point is $(0,0)$

- target point is in the north direction

$\cdot \theta_{0}=\left\{15,30,45^{\circ}, 60^{\circ}, \ldots\right\}$

and the results are shown in Figures 3 and 4.

-Fig. 3 shows the actual mission for $\theta_{0}=60^{\circ}$ and for

-Fig. 4 shows the actual missions for constant burn-out time and different $\Theta_{0}$

It is clear that the attitude errors for different missions have settled to within 2 degrees in a settling time of approximately
one-third of the burn-out time.

\section{3-THRUST UNCERTAINTY FORMULATION}

The total impulse of the solid propelient rocket motor depends on the chemical compound and the burning rate. The thrust-time profile depends on the form function and the the form function and of burning. Theburn-out time depends on uncertain. Accordingly, the burning rate, so it is also uncertainties due to produe thrust profile may suffer from environmental conditions. These as randomness in the profile shape parameters. For the prape parameters.

Fig. 5 is considered, where:
Fimplified thrust-time curve shown in 
${ }^{-} \mathrm{F}_{1}$ (initial thrust value), $\mathrm{M}_{1}$ (slope of the segment $\mathrm{F}_{3} \mathrm{~F}_{2}$ ), $\mathrm{S}_{1}$ (area under the segment $\mathrm{F}_{1} \mathrm{~F}_{2}$ ), and $\mathrm{S}_{2}$ (the remaining area) are considered as Gaussian distributed random variables.

Random function generators are used to generate $F_{1 i}, M_{1 i}, S_{1 i}$, and $S_{2 i}$ where $i$ is the trial number.

A population of 100 samples is simulated and the limiting curves are shown in Fig.5. The corresponding distribution of $t_{b}$ is shown in Fig-6. Where the random variations in $t_{b}$ are within 2 seconds. The generated thrust-time profiles (100 trials) are sorted w.r.t. $t_{b}$ in an ascending order and for each case the impact range is calculated through a 3-dimensional simulation procedure. As shown

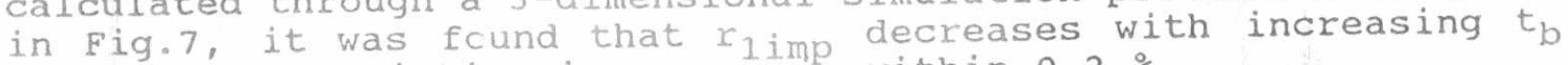
and that the variation in $r_{1 \text { imp }} \mathrm{Is}_{\mathrm{s}}$ within $0.2 \%$

The determination of timp can be carried out through:

1-nominal trajectory off-line simulation

2-statistical means

3-software sensor

For the present case study, the components of the gravitational acceleration $G_{e l}, G_{e}$ are nearly constant for a specific mission, i.e their variation with respect to time is negligible, but they may differ from nominal.

\section{4-GUDIANCE CORRECTION ALGORITHM}

\section{1-Simplified Free Space Fire Plane Motion Equations}

Under the assumption that:

- launch point is at $(0,0)$

thus : $r_{1}(t)=x_{e}(t)$

$r_{2}(t)=y_{e}(t)-R_{e}$

-target point in the north dixection

- earth gravity components $\mathrm{G}_{\mathrm{e}}=0 ; \mathrm{G}_{\mathrm{e}}=-\mathrm{g}_{0}$.

the free space fire plane motion equations are:

$\begin{array}{llll}\dot{r}_{1}=v_{\text {el }} & \dot{r}_{2}=v_{\text {e2 }} & \dot{v}_{\text {el }}=0 & \dot{v}_{\text {e2 }}=-g_{0} \\ \dot{\mathrm{w}}_{z 1}=0 & \dot{I}_{2}=0 & \dot{J}_{1}=0 & \dot{J}_{2}=0\end{array}$

with initial conditions:

$$
\begin{array}{llll}
r_{1}(0)=r_{1 b} & r_{2}(0)=r_{2 b} & V_{e 1}(0)=V_{e 1 b} & V_{e 2}(0)=V_{e 2 b} \\
W_{Z 1}(0)=0 & & & \\
I_{1}(0)=I_{1 b} & I_{2}(0)=I_{2 b} & J_{1}(0)=J_{1 b} & J_{2}(0)=J_{2 b}
\end{array}
$$

Hence; the states affecting the free space ballistic missile motion are $r_{1}(t), r_{2}(t), v_{e 1}(t), V_{e 2}(t)$. 
$r$

4.2- Solution of the equations describing the free space
missile motion in the fire plane:

The solution of the above system of equations represents a look ahead predictor for $t_{\text {imps' }} r_{\text {imps }} a t t_{b}$ as follows:

$r_{1}(t)=r_{1 b}+(t-t b) v_{e} b$

$r_{2}(t)=r_{2 b}+(t-t b) v_{e 2 b}^{e 1 b}-1 / 2 g_{0}(t-t b)^{2}$

$V_{e l}(t)=V_{e l b}$

$v_{e 2}^{e 1}(t)=v_{e 2 b}^{e} g_{0}(t-t b)$

at $t=$ timp :

$r_{1 \text { imps }}=r_{1 b}+(t i m p s-t b) v_{e} b$

$\begin{aligned} r_{2 i m p s} & =r_{1} b^{+}\left(t_{i m p s}-t b\right) v_{e} v^{2} b-1 / 2 g_{0}(t i m p-t b)^{2} \\ t_{i m p s} & =t_{1}+2 r_{2}\left(t_{1}\right) / g_{0}\end{aligned}$

where: $t_{1}=t_{b}+v_{e 2 b} / g$

$$
r_{2}\left(t_{1}\right)=r_{2 b}+\left(t_{1}-t_{b}\right) v_{e 2 b}-\frac{1}{2} g_{0}\left(t_{1}-t_{b}\right)^{2}
$$

4.3-The Nature of $\underline{\text { imps }}, \underline{t_{\text {imps }}}$

For the specified mission $\left(\theta_{0}=60^{\circ}\right)$, and through one hundred shootings (for $t_{b}$ sorted in an ascending order), the performance of the proposed software algorithm is compared with that rielded performance); Figures 7 and developed mathematical model iactual. are nearly constant with respect to $t_{\mathrm{b}}$ similar to thps ana $t_{\text {imps }}$ and $t_{i m p}$, nevertheless there is some error to the actua $r_{\text {r }} r_{\text {imp }}$ w.r.t.tbo). This error tharly constant - more accurate represe

-more accurate calculation of the gravity model.

the spherical shape

-making use of perturbation technique

4.4-Burn-out impact point transition perturbations :

$\delta r_{1 i m p}=\delta r_{1 b}+(t i m p-t b) \delta v_{e l b}$

$\delta r_{2 i m p}=\delta r_{2 b}+(t i m p-t b) \delta v_{e 2 b}$

4.5 Guidance Correction Demand Formulation

For annulling the error at impact $\left(\delta r_{1 i m p}=0 ; \delta r_{2 i m p}=0\right)$ then:

$0=\delta r_{1 b}+(t i m p-t b) \delta v_{e l c}$

$0=\delta r_{2} b+(t i m p-t b) \delta v_{e 2 c}$

where:

$\delta V_{e l c}, \delta V_{e 2 c}$ are the command perturbations:

$\delta v_{e 1 c}=\frac{-\delta r_{1 b}}{t i m p-t b} \quad ; \quad \delta v_{e 2 c}=\frac{-\delta r_{1 b}}{t i m p-t b}$ 
r According to Fig. 2 the mission is described by $\Gamma_{r}$, and the guidance correction demand will be formulated as follows:

$$
\begin{aligned}
& \Gamma=\tan ^{-1}\left(v_{e 2} / v_{e 1}\right) \quad ; \quad \Gamma=\frac{v_{e 1} v_{e 2}-v_{e 2} v_{e 1}}{v_{e 1}^{2}} \\
& \delta \dot{\Gamma}=\left[\frac{\dot{v}_{e 2}}{v^{2} e_{e 1}+v^{2}{ }_{e 2}}-\frac{2 v_{e 1}\left(v_{e 1} v_{e 2}-v_{e 2} v_{e 1}\right)}{\left(v_{e 1}^{2}+v_{e 2}^{2}\right)^{2}}\right] \delta v_{e l c}+ \\
& {\left[\frac{-v_{e l}}{v^{2} e 1+v^{2} e 2}-\frac{2 v_{e 2}\left(v_{e 1} \dot{v}_{e 2}-v_{e 2} \dot{v}_{e 1}\right)}{2\left(v_{2 e 1}+v_{2 e 2}\right)}\right] \delta v_{e 2 c}-} \\
& {\left[\frac{v_{e 2}}{v^{2} e 1+v^{2} e 2}\right] \delta v_{e l}+\left[\frac{v_{e l}}{v^{2} e^{+v_{2 e 2}}}\right] \delta \dot{v}_{e 2}}
\end{aligned}
$$

$\delta \dot{\Gamma}_{r}$ is calculated for $t \geq t_{\text {bso }}$

\section{5-RESUITS}

For evaluating the proposed guidance correction algorithm the impact accuracy is used as a criterion.

Fig.9. illustrates the impact error $\delta r_{1 i m p}$, versus burn-out time, for uncompensated and compensated cases respectively.

Fig.10. shows the impact error distribution for both cases. The corresponding statistical parameters can be summarized as follows

\begin{tabular}{|l|c|c|}
\hline Impact Error & Uncompensated & Compensated \\
\hline Mean $(M)$ & 1.044 & 0.001 \\
Dispersion $(\sigma)$ & 0.460 & 0.160 \\
CEP & 0.306 & 0.037 \\
\hline
\end{tabular}

\section{6- CONCLUSION}

Due to production tolerences and off-nominal environmental conditions, solid propellent thrust time profile has a random character in both magnitude and burn out time. This character leads to uncertainties in the motion parameters near burn out, and consequently the impact point is highly erroneous.

The proposed guidance correction algorithm compensates for these uncertainties through transition relations relating the perturbations near burn out to the impact error. The CEP is improved about 10 times and with some sophistications more improvements are attainable. 


\section{REFERENCES}

[1]J.W. Cornlisse, H.F.R.Schoyer and K.F.Wakker, "Rocket propulsion and space Flight Dynamics." Pitman publishing [2]George R.Pitman, JR.,"Inertial Guidance."John Willey \& Sons, New
York 1962.

[3] Arthur L.Greensite," Analysis and Design of Space Vehicle Flight Control systems "Spartan Books, New York, 1970

[4]Hideo Ikaw," A unified Three Dimensional Trajectory simulation Methodology.J.Guidance\& Control, vol.9, No.6, 1986.

[5]K.R.Britting, "Navigation Analysis", Willy Interscience, 1971.

[6]Elleithy, Tantawy, Ghoniemy," Development of a six degrees of missiles " missiles." , Third ASAT Conference, MTC, Cairo, Egypt, 1989

[7]W. Templman," Linear Guidance Laws For Space Missions". The charles starck Droper Laboratory, Inc. 552 Technology Square, Gambidge, Massachusetts 02139., American Institude of Aeronoutics and Astronautics Inc. 85- 1915, 1985.

[8]Jhon W.Hardtle, Michael J.Plehhler Jerre E.Bradt," Guidance Requirements For Future Launch Vehicle" American Institute of
Aeronautics and Astronautics.Inc., 87-2462, 1987.

[9]Salem A.K.Al-Assadi and Lamya A.M.Al chalabi, "Optimal Gain For Proportionol Integral Derivative Feedback" "IEEE Control

\section{NOMENCLATURE}

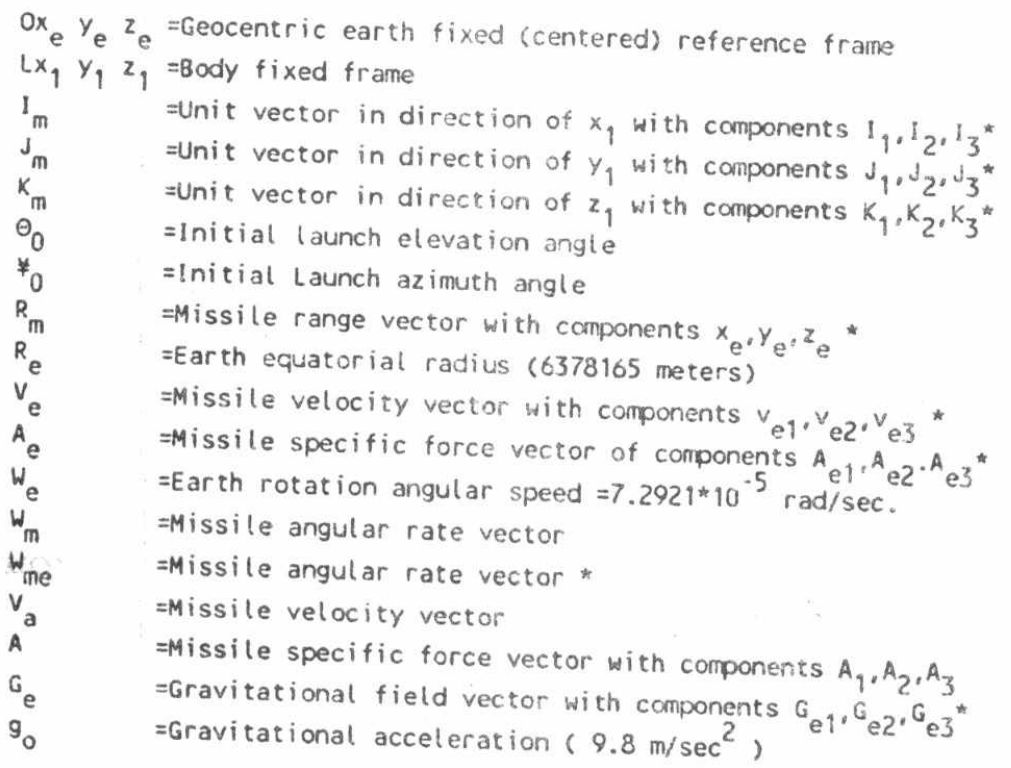


$\mathrm{H}_{3} \quad$ Missile angular momentum vector $=\mathrm{J} . \mathrm{H}_{\mathrm{m}}$

1

=Missile moment of inertia w.r.t. its axes

=Aerodymanic force vector

ilhrust force vector

=Aeradynamic moment vector

=Thurst moment vector

=nissite mass

mass

Flight path tangent angle
$\Gamma_{0}$

$r_{5} \quad=$ Real $f t$ ight path tangent angle

${ }^{F}$

=Magnitude of total thrust of rocket notor $\left[\mathrm{kg} . \mathrm{m} / \mathrm{sec}^{2}\right.$ ]

=8urn out time

timp $=1$ meact time at target

timps =lmpace time predicted by the proposed algorithm

$r_{10} \quad$ =Burn out downrange

$r_{2 b}=$ Burn out height

velb =8urn out down velocity

verb

$r_{1 \text { imo }}$

$r_{1 \text { imps }}$

rimp

'2imps

$s_{2}$

$u_{d}^{2}$

toso

=Burn out height velocity

$\Rightarrow$ Down impact range

=0own impact range predicted by the proposed algorithm

=height impact range

= Height impact range predicted by the proposed algorithm

=Nozzle deflection

=Control demand

=starting time for correction

=circular propable error

=in earth coordinate system

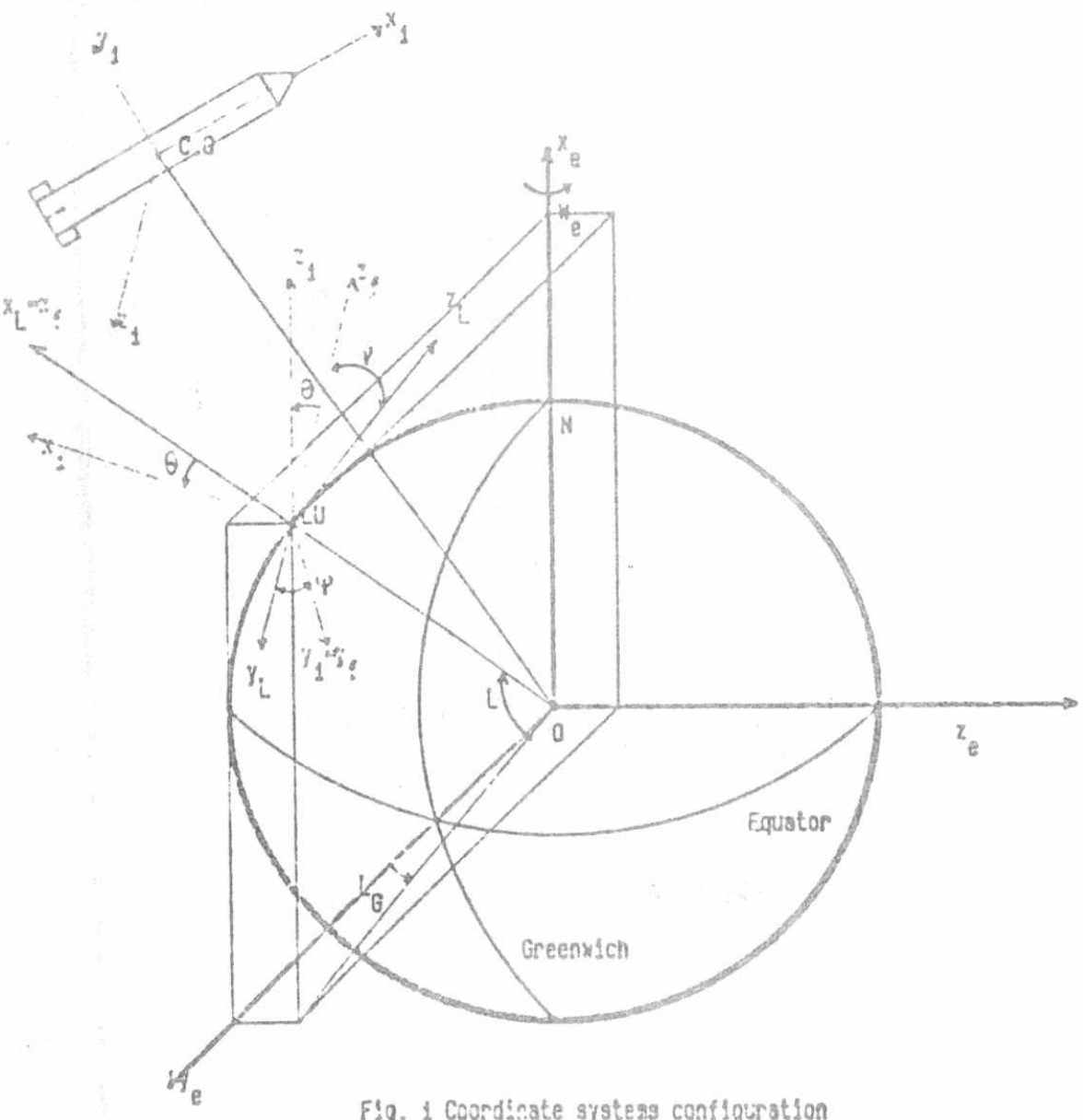

F!g. I Coondinate syateas conf1guration 


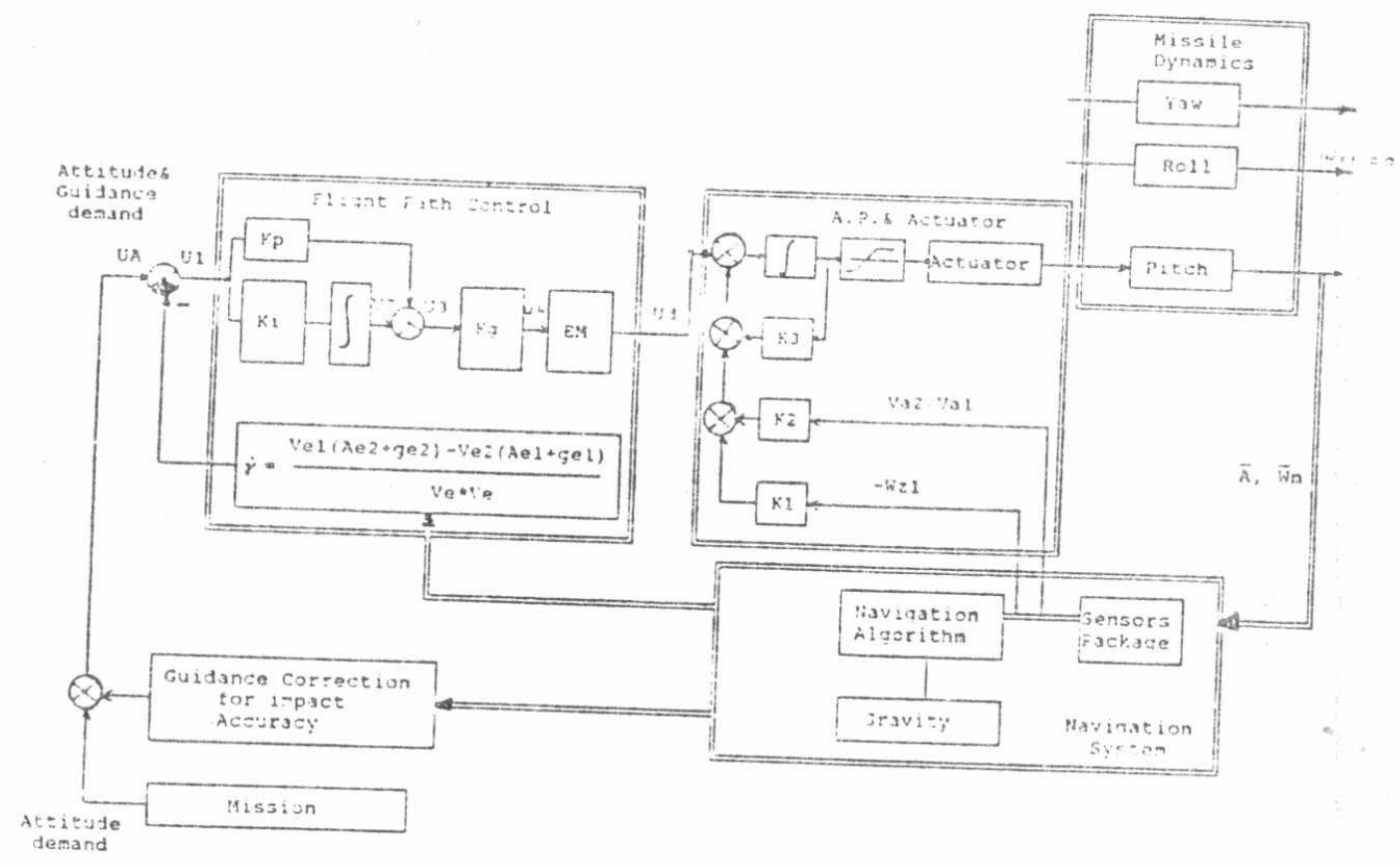

Fig.2. Ballistic Missile Control scheme in the Fire plane

$\Gamma($ Degrees )

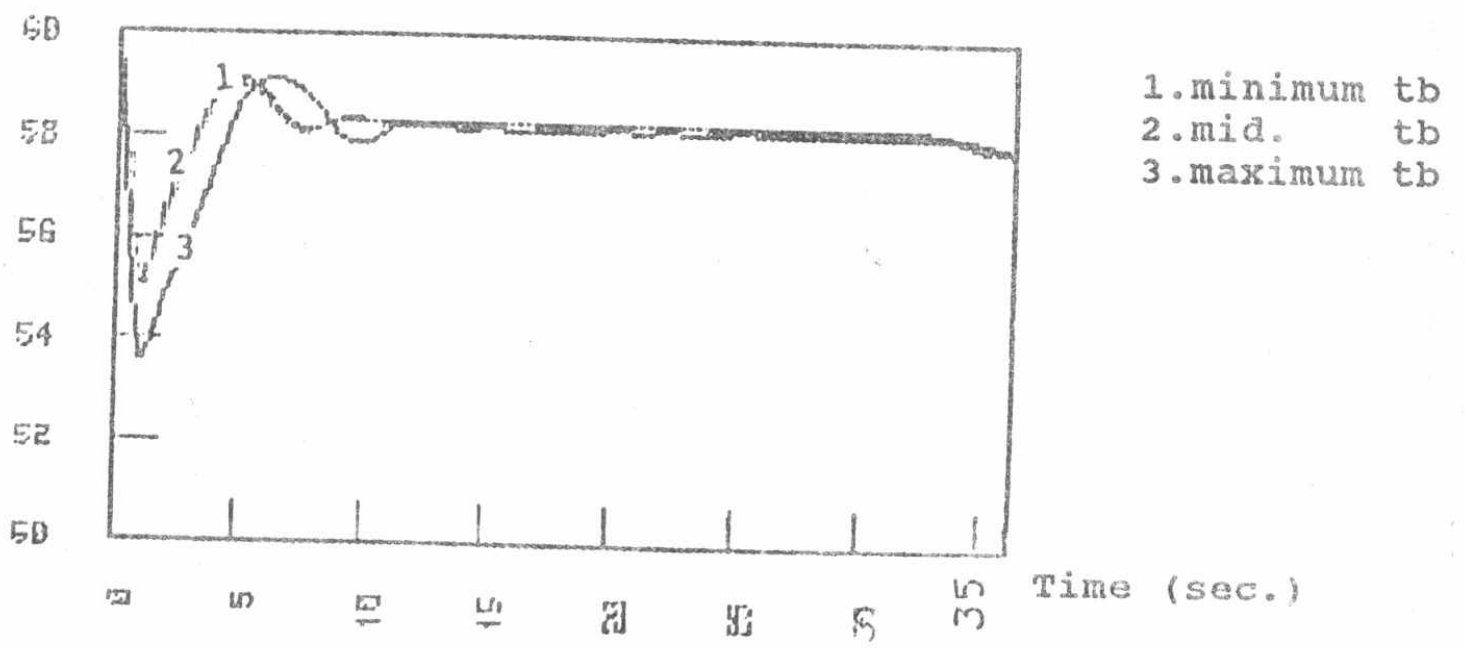

Fig.3.Flight path response for different tb 


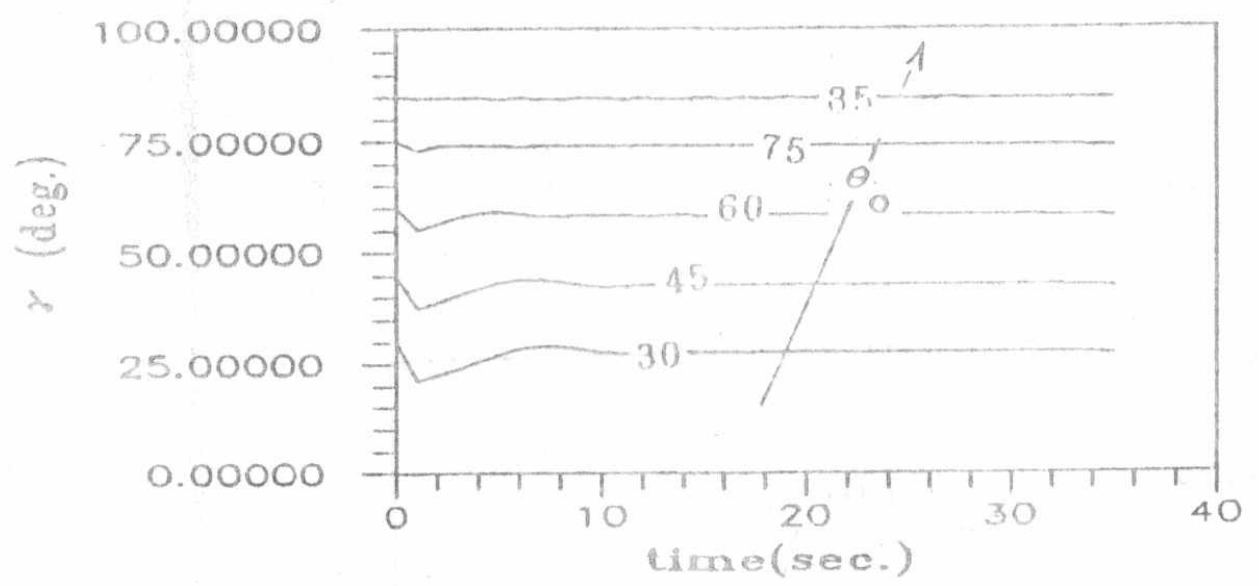

Fig. 1.Flight path response for different missions

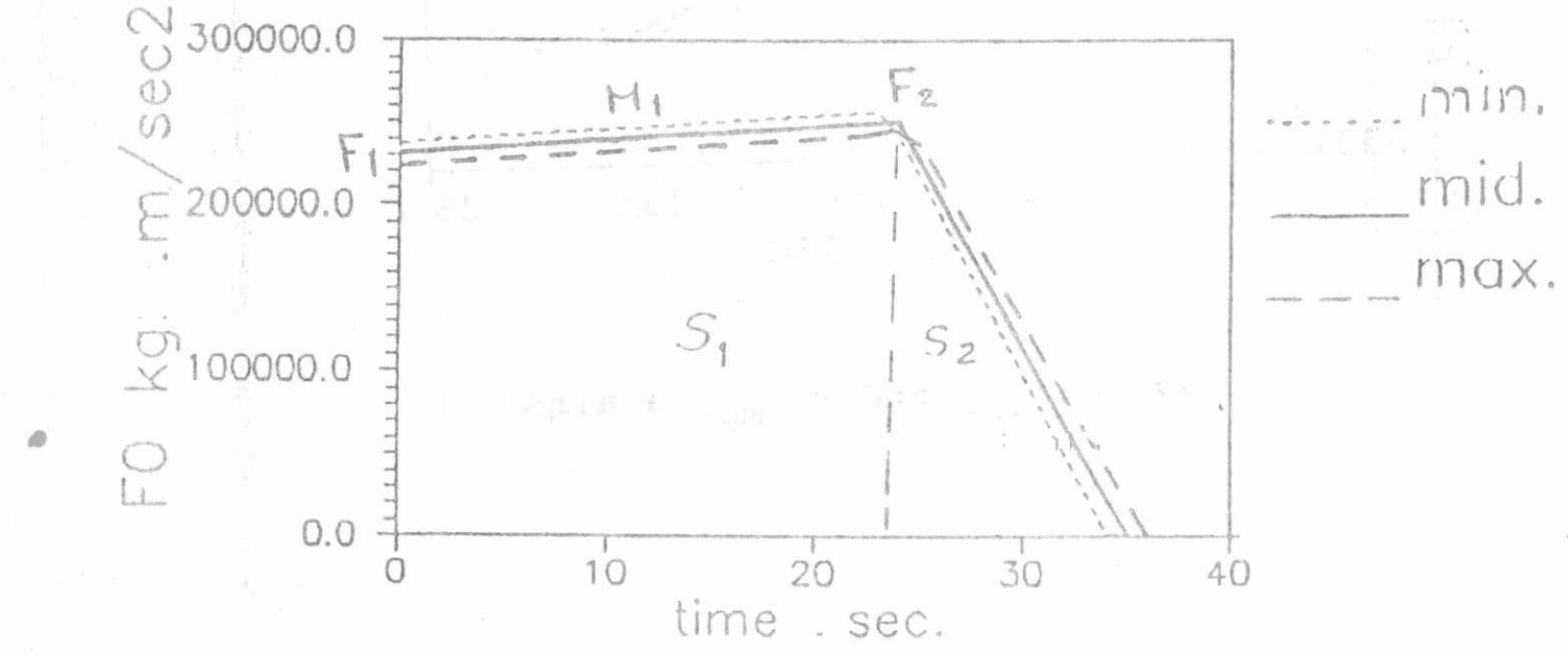

Fig.5. Simulated thrust

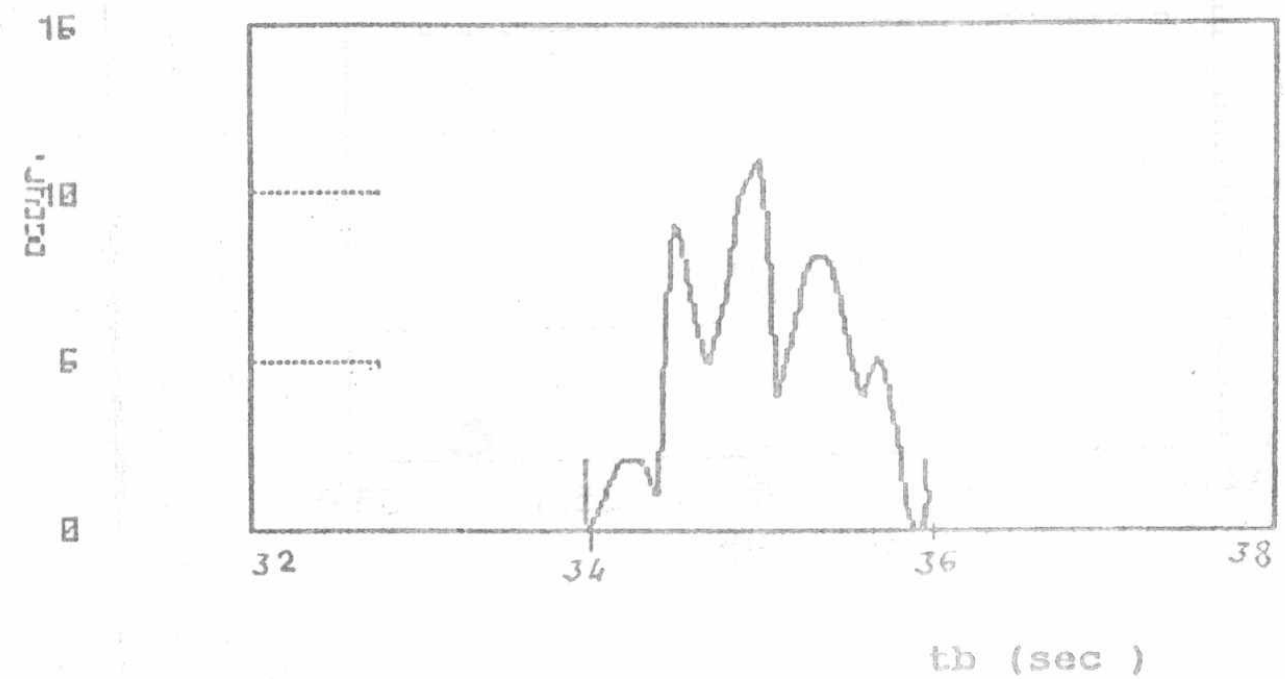

Fig.6. tb Distribution 


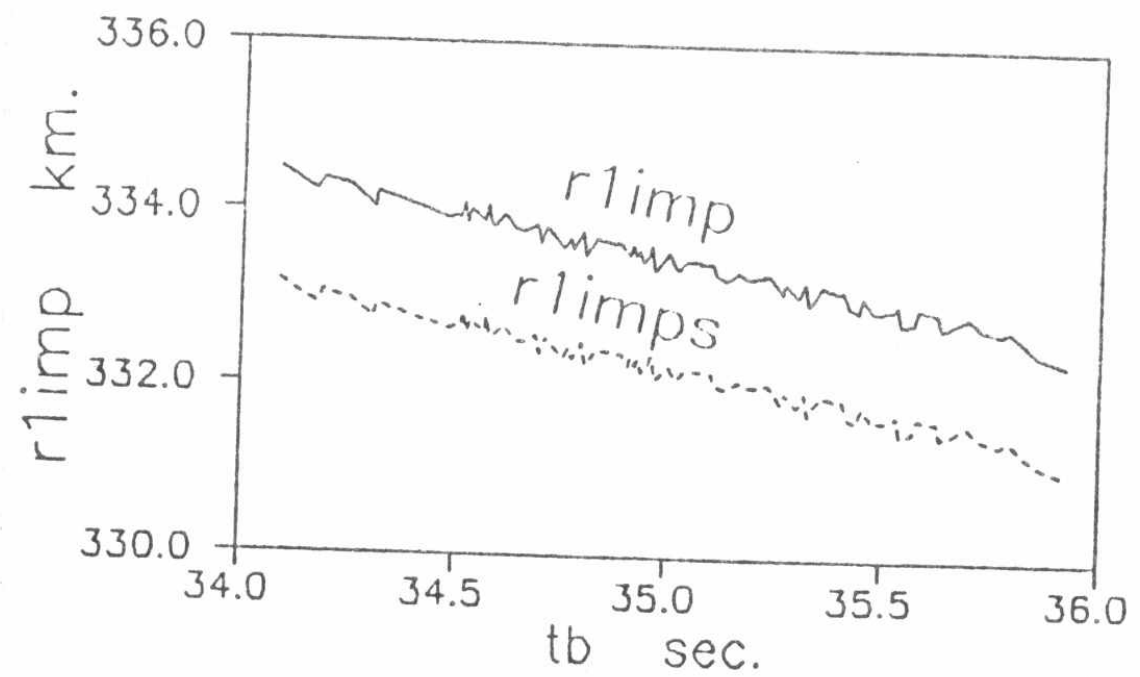

Fig.7. $r_{\text {imp }}$ and $r_{\text {limps }}$ against tb

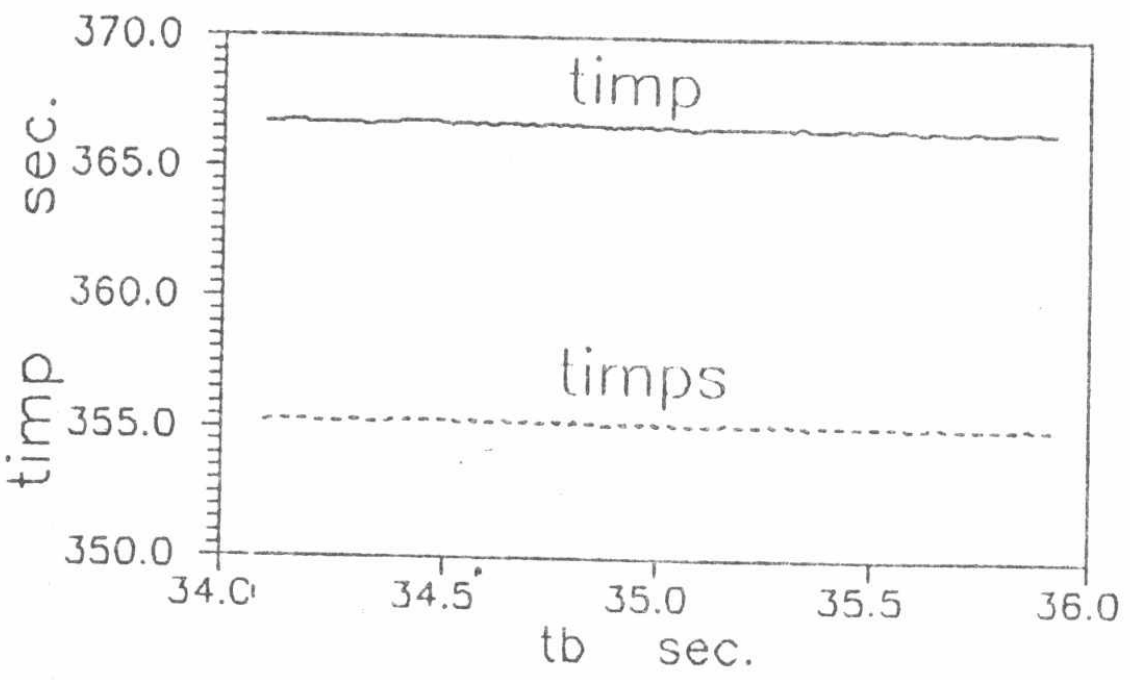

Fig.8.t $t_{\text {imp }}$ and $t_{\text {imps }}$ against tb 


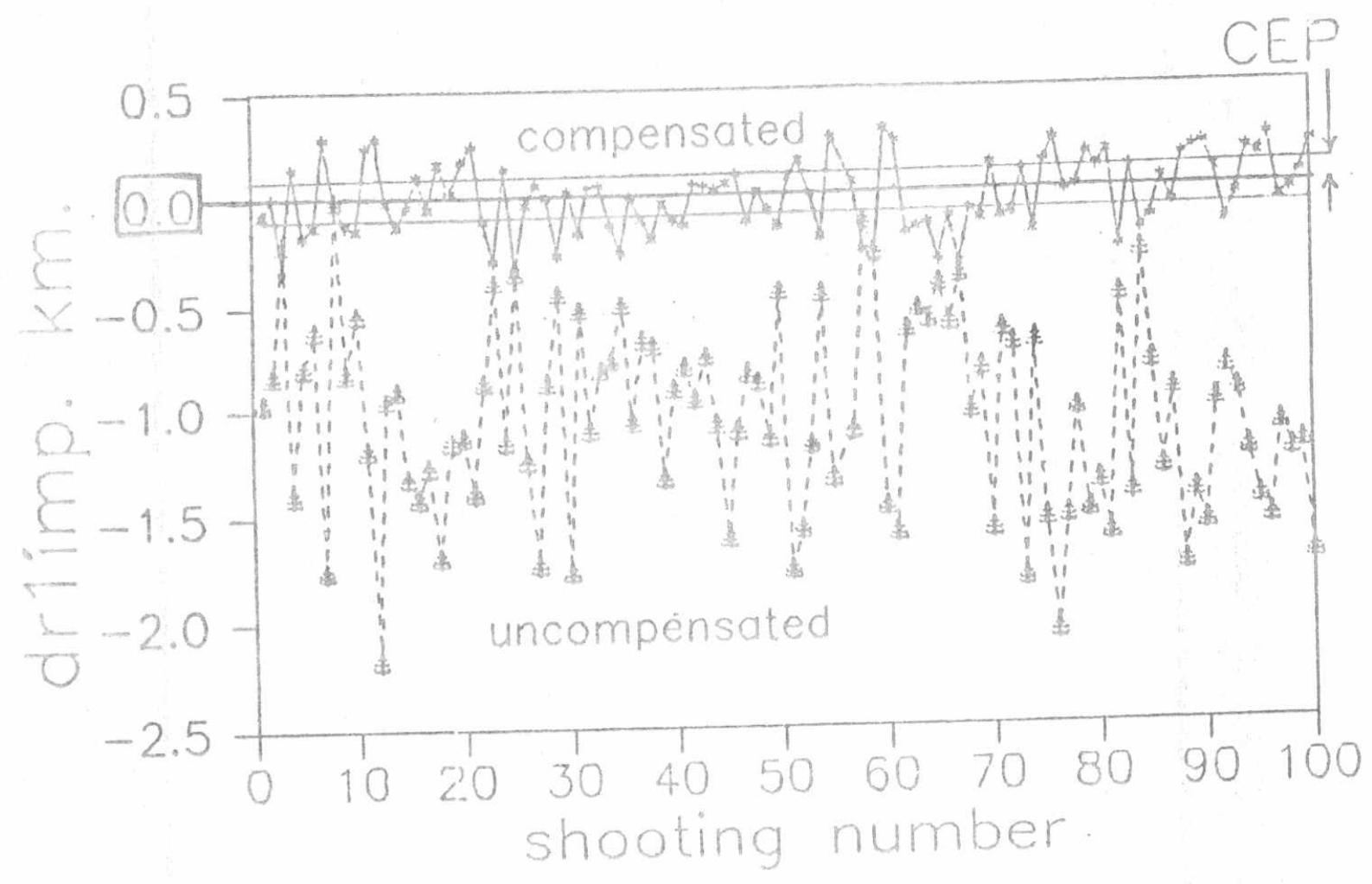

Fig.9. Impact exrox evaluation

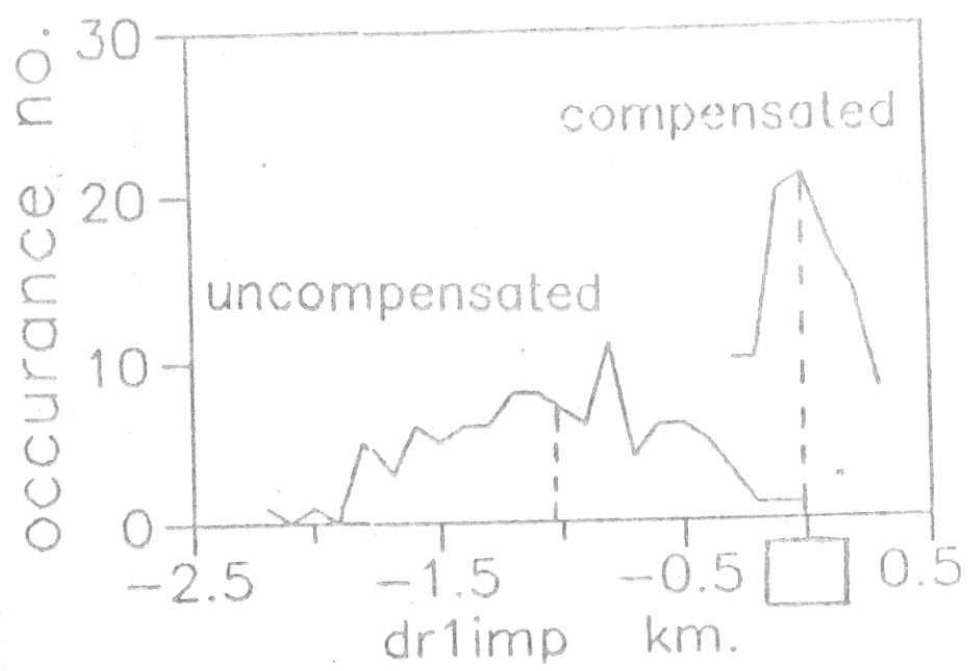

Fig.10. Impact exrox distribution 